\title{
Degree Phrase Raising in Relative Clauses
}

\section{Citation}

Szczegielniak, Adam. 2013. “Degree Phrase Raising In Relative Clauses." In Information Structure and Agreement, ed. Victoria Camacho-Taboada, Ángel L. Jiménez-Fernández, Javier Martín-González, and Mariano Reyes-Tejedor, 255-274. Amsterdam: John Benjamins Publishing Company.

\section{Published Version}

10.1075/la.197

\section{Permanent link}

http://nrs.harvard.edu/urn-3:HUL.InstRepos:29441924

\section{Terms of Use}

This article was downloaded from Harvard University's DASH repository, and is made available under the terms and conditions applicable to Other Posted Material, as set forth at http:// nrs.harvard.edu/urn-3:HUL.InstRepos:dash.current.terms-of-use\#LAA

\section{Share Your Story}

The Harvard community has made this article openly available.

Please share how this access benefits you. Submit a story.

\section{Accessibility}


In: Information Structure, Agreement and CP.

Camacho Taboada, Jiménez Fernández, Martín González, Reyes Tejedor (Eds)

John Benjamins. Amsterdam (2012). pp. 255-274.

\section{Degree Phrase Raising in Relative Clauses. ${ }^{*}$}

Adam Szczegielniak

Rutgers University

adam.s@post.harvard.edu

http://scholar.harvard.edu/adam

In this paper I will argue that modal degree of amount relative clauses, as well as Spanish AP degree relative clauses, are derived via overt DegP raising. I show that the two types of degree relative clauses discussed here are mirrored by two types of DegP that were proposed in Neelman, van de Koot and Doetjes (2004). This raises the possibility that the syntactic and semantic differences of the classes of degree constructions can be reduced to the type of lexical item that is raised out of the CP.

Keywords: Degree Phrase; relative clause

\section{Two types of degree relativization}

The paper argues that relative clauses can be derived via overt raising of the Degree Phrase (DegP) out of the CP. I concentrate on two types of degree relative clauses: modal degree of amount relatives (1) as first discussed in Heim (1987), and Spanish adjectival degree clauses (2), as discussed in Gutiérrez-Rexach (1999). I aim to show that both types of constructions are derived via overt DegP raising. Differences between (1) and (2) will be argued to be a reflex of the dual nature of DegP which can behave like a modifier in Spec-XP or as a head taking an AP as its complement (Neelman, van de Koot and Doetjes 2004).

(1) It would take us all year to drink the champagne that you spilled at the party A. the amount of champagne.

\#B. the actual champagne.

* The research leading to these results has received funding from the European Community's Seventh Framework Program (FP7/2007-2013) under grant agreement n ${ }^{\circ} 224943$. I would like to thank Cedric Boeckx, Victor Manfredi, and two anonymous reviewers for comments on the text. I would also like to thank for their comments: Gennaro Chierchia, Noam Chomsky, Guglielmo Cinque, Clemens Mayr, Masha Polinsky, Anna Szabolcsi, Edwin Williams, Dorota Wojtaś, Jim Wood, and the audience of 21 Colloquium on Generative Grammar at University of Seville and University Pablo de Olavide. A special thank you to Javier Martín-González and Benjamin Feldshuth. All errors are mine, but no refunds please. 
(2)

Juan no entendió lo hermosa que era la

Juan not understood the-neut. beautiful-fem.sg. that was the-fem.sg.

novella

novel- fem.sg.

'Juan did not understand how beautiful the novel was'

A. Juan did not understand the extent of the beauty of the novel'

\#B. Juan though the novel was not beautiful.

The derivation of both (1) and (2) involves DegP moving overtly out of its base position inside the CP. DegP raises to Spec-CP where it undergoes Maximization, in fashion similar to comparatives (von Stechov 1984). ${ }^{1}$ Unlike in comparatives, this movement is overt, and, unlike in comparatives, DegP overtly raises out of CP. In other words, (1) and (2) differ from (3) below in two respects: in relative clauses: (i) DegP raises overtly, and (ii) DegP raises out the CP to a position within the extended DP.

(3) It would take me all year to drink as much beer as you spilled wine at the party

This paper will not discuss in depth the constructions classically assumed to be degree/amount relative clauses. ACD relative clauses (Carlson 1977), such as (4), will not be discussed at all since a discussion about the interaction of ellipsis and relativization would take us too far afield (see: Herdan 2008).

(4) John took the books that he could

\footnotetext{
${ }^{1}$ Maximization takes sets of degrees and choses the one with the largest cardinality. This captures the intuition that in:

(i) John was taller than every boy in the class

we are comparing John's degree of tallness with the degree of tallness of the tallest boy in the class.
} 
Existential 'there' relatives (5) are also considered to be degree/amount relative clauses (but see Herdan 2008, and McNally 2008). I will postpone the discussion of constructions like (5) until the end of the paper. This will allow to lay the groundwork to argue that examples like (5) are derived like the Spanish example in (2).

(5) John took the books that there were on the table

This paper is organized as follows. Section 2 examines head noun reconstruction properties of examples like (1). Lack of reconstruction effects will be used as an argument against a head noun raising derivation of (1) as proposed in Grosu and Landman (1998). As an alternative, a derivation where DegP raises but the NP's are derived via matching is proposed. Section 3 discusses difference in scope between comparatives (3) and relatives (1) these observations will be used to argue that $\mathrm{DegP}$ raises out of $\mathrm{CP}$ in degree relative clauses. Section 4 introduces the two types of DegP and shows that the contrast between (1) and (2) can be reduced to differences in DegP behavior. Section 5 examines determiner restrictions in both (1) and (2). It is argued that the lack of agreement between the determiner and AP in Spanish can be accounted within the framework proposed here. Section 6 extends the analysis of examples like (2) to existential 'there' relatives and offers tentative speculation concerning the modal requirement for degree of amount readings in examples like (1).

\section{Degree Relative Clauses and Head Noun Raising}

There are two major competing approaches to the derivation of relative clauses: a matching derivation vs. a head noun raising one (for an overview see: Sauerland 1998, 2003). The difference boils down to whether the head noun in externally headed relative clauses is related with the gap inside the clausal modifier via movement, or via ellipsis, of an identical copy. The approach adopted for degree relative clauses in Carlson (1979), Grosu \& Landman (1998) is that degree relative clauses are derived via head noun movement. Grosu \& Landman (1998) propose that DegP raises with the head noun to a $\mathrm{CP}$ peripheral position, and then the head noun raises further out of the CP in a fashion similar to the one proposed in Kayne (1994). 
6. A derivation of (1) following Grosu and Landman (1998)

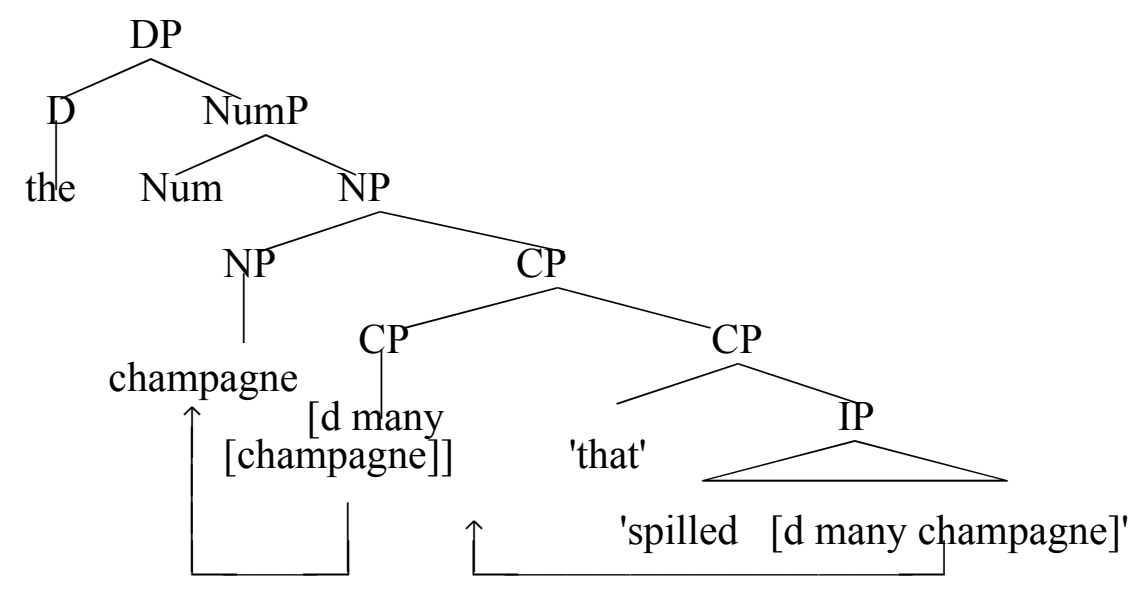

A raising analysis predicts that, other things being equal, the head noun should be able to reconstruct to its base position, just like in any other case of A'-movement (Vergnaud 1974). The derivation in (6) makes the prediction that a degree relative like (1) should be allowed to have an interpretation where the head noun is reconstructed inside the relative clause. This appears to be not the case. Consider the following set of data that involves making the head noun part of an idiom inside the $\mathrm{CP}$, and an example where the head noun has a reflexive that can only be interpreted inside the CP. In both cases, the judgments appear to indicate that the head noun cannot be interpreted inside the $\mathrm{CP}$ if it is part of a modal degree of amount relative clause.

(7) At the morgue, it would take us just a day to get the creeps that a cemetery gives in a year $^{2}$

A. Literal meaning: creeps are items

${ }^{\#} \mathrm{~B}$. Idiom reading involving the degree of the amount of creeps

${ }^{2}$ It has to be noted that this idiom does lend itself to be relativized with give/get (Svenonius 2005).

(i) At the morgue I get the creeps that only a cemetery gives 
(8) It would take us all year to paint the portraits of himself $f_{i}$ that $\mathrm{John}_{\mathrm{i}}$ burned in a fit of paranoia
${ }^{\#}$ A. Type of portrait
B. painting the actual burned canvas
\#C. paint the amount of portraits.

The above examples indicate that classical head noun reconstruction tests point to a matching derivation (Lees 1960, Chomsky 1965, Munn 1994, Sauerland 1998), as opposed to head noun raising analysis adopted in Grosu \& Landman (1998), based on the proposals in Kayne (1994). When we eliminate the possibility of an amount reading by removing the modal would (see Heim 1987), we obtain a well-formed relativized idiom. ${ }^{3}$

(9) At the morgue, it took us just a day to get the creeps that a cemetery gives in a year Furthermore, if we remove the reflexive in (8), we can again obtain a degree of amount reading.

(10) It would take us all year to paint the portraits of Roger that $\mathrm{John}_{\mathrm{i}}$ burned in a fit of paranoia
${ }^{\#}$ A. Type of portrait
B. painting the actual burned canvas
C. paint the amount of portraits

The above contrasts indicate that interpretation of the head noun inside the $\mathrm{CP}$ is incompatible with a degree of amount reading in modal degree relatives. The proposal of this paper is that modal degree relative clauses are derived via head noun matching. The internal NP does not raise outside the $\mathrm{CP}$, and what is pronounced is an identical copy outside the CP. This accounts for the lack of head noun reconstruction effects. The question is how do we obtain a

\footnotetext{
${ }^{3}$ The mechanism that makes the presence of the modal obligatory is not well understood; however, removing it does lead to a non-degree reading, even in the case of (1):

(i) It took us a year to drink the champagne that you spilled
} 
degree reading? I propose a DegP is generated in a position modifying the internal NP, for example Spec-NP. ${ }^{4}$ Instead of NP raising out of the CP, I suggest that DegP is raised out of CP and shared between the internal and external NP. This means that the structure of the external DP is built 'dynamically' via movement of material from inside the CP. After DegP raising, the inner $\mathrm{NP}$ is deleted under identity as is assumed in standard matching accounts. This alleviates potential LBE violations. Following Merchant (2001), it is known that ellipsis alleviates LBE violations as indicated in the examples below (strikethrough indicates ellipsis).

*(11) He wants a detailed list, but I don't know [how detailed] $]_{1}$ he wants a $t_{1}$ list (12) He wants a detailed list, but I don't know [how detailed $]_{1}$ he wants a $t_{4}$ list

Obligatory ellipsis accounts for the inability of pronouncing the internal NP in relative clauses. This is in contrast to comparatives where, as Grosu and Landman (1998) point out, the sortal NP's can be different.

*(13) It would take us all year to drink the champagne that you spilled beer at the party (14) It would take us all year to drink as much champagne as you drank beer at the party

An analysis involving DegP raising out of $\mathrm{CP}$ also captures the fact that degree of amount relative clauses do not stack. The example below is impossible if we are talking about the amount of soup and not the actual substance.

*(15) It would take us a year to drink the soup that you spilled that your boyfriend cooked

Grosu and Landman (1998) argue that the lack of stacking is an indicator that the semantics of the relative clause are computed CP internally. However, this cannot be correct since in languages like Polish stacking is impossible in restrictive relative clauses as shown in

\footnotetext{
${ }^{4}$ Thus I assume that non-degree readings of examples like (1) are due to a lack of DegP in SpecNP.
} 
(16) below, and yet they exhibit all the hallmarks of head noun reconstruction as documented in Szczegielniak (2005).

*(16). Lubię tę zupę, co/którą przyniosłeś, co/którą twój chłopak ugotował Like that soup that/which brought that/which your boyfriend cooked 'I like the soup that you brought that your boyfriend cooked'

This leads me to believe that CP internal semantics cannot be the only reason why there is no stacking in relative clauses. Otherwise, Polish restrictive relative clauses would have to have a similar semantics to English degree relatives, and different one from English restrictives. In the approach adopted here, there is a simple explanation for the lack of stacking in degree relative clauses. Degree of amount relative clauses do not stack because only one DegP can be Merged with the external head noun. This syntactic requirement forces a 1-1 matching between head nouns and their CP modifiers. Such an explanation has the advantage that it does not tie stacking to a single semantic interpretation.

The above facts lead to propose a mixed derivation of degree of amount relative clauses. The NP's are derived via matching and DegP is derived via raising. ${ }^{5}$ The derivation involves DegP being generated in Spec-NP $\mathrm{N}_{\mathrm{j}}$ and raising with the whole NP to a Spec-Topic position in order to license subsequent ellipsis of the inner NP, making NP deletion under identity of form of Topic drop (Ross 1982, Huang 1984). In that sense, this analysis utilizes the same mechanism used in accounts that utilize a head noun raising derivation also assume that the head noun raises to a Spec-Topic position (Bianchi 1999, de Vries 2002). ${ }^{6}$

${ }^{5}$ I skip the issue of how much DP structure is present in the internal NP. It does not appear relevant for this analysis whether inside the CP there is a full DP or not.

${ }^{6}$ As one anonymous reviewer points out, Grosu and Landman (1998) do not assume movement to Spec-Topic. However, I do not think that this has any bearing on the analysis here. I assume there is NP topicalization in order to account for intuition that the internal head noun is a topic, and to be consistent with the proposals in Szczegielniak (2005) that topicalization licenses ellipsis. 
It would take us all year to drink the champagne that you spilled at the party $\left(\mathrm{N}_{\mathrm{i}}=\mathrm{N}_{\mathrm{j}}=\right.$ champagne, strikethrough = ellipsis under identity)

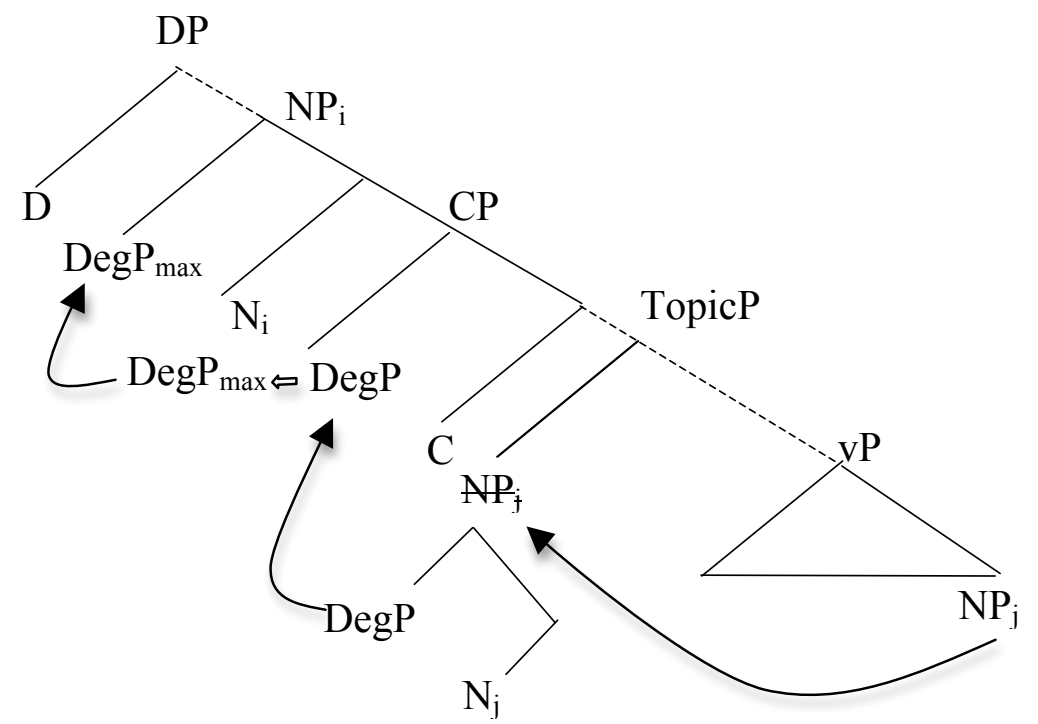

The difference between those accounts and the one proposed here is that in modal degree relatives the NP does not raise any further than Spec-Topic. This accounts for the lack of head noun reconstruction; a matching analysis predicts that the idiomatic reading is lost if there is no movement chain between the head noun and the idiom trace inside the relative clause (Vergnaud 1974). The same holds for Condition-A effects, if there is no movement relationship between head noun containing the reflexive and the trace position - where the reflexive is bound by the subject, then the construction is predicted to be ungrammatical. This proposal not only correctly predicts the head noun reconstruction facts in modal degree relative clauses, it also captures how they differ from comparatives.

\section{Comparatives vs. relatives}

In this paper I am arguing for a derivation of modal degree relative clauses that involves overt DegP raising via $\mathrm{CP}$ to a position modifying the external NP. The trigger for this movement is a non-interpretable $\{+$ REL $\}$ feature (Rizzi 1997) on CP. The need to check this feature forces DegP to raise in the syntax. This is not the case in comparative constructions where there is no $\{+\mathrm{REL}\}$ feature present that would trigger overt DegP raising. I argue that this difference in the 
derivation of comparatives and modal degree relatives leads to different readings as far as scope is concerned. In the relative and in the comparative constructions shown below (example 18 vs. 19), the quantifier every is argued to be in a different configuration in relation to both $\operatorname{Deg} \mathrm{P}_{\operatorname{MAX}}$ and DegP.

(18) It would take me all year to drink the champagne that every guest spilled at the party A. Amount of champagne drank = sum of the amount of spilled champagne by each individual guest \#B. Amount of champagne drank = amount of spilled champagne by the guest who spilled the most

C. Amount of champagne drank = amount of spilled champagne by any of the guests provided everyone spilled equal amounts

(19) It would take me all year to drink as much champagne as every guest spilled beer at the party $^{7}$

\#A. Amount of champagne drank = sum of the amount of spilled beer by each individual guest

B. Amount of champagne drank = amount of spilled beer by the guest who spilled the most

C. Amount of champagne drank = amount of spilled beer by any of the guests provided everyone spilled equal amounts

The crucial contrast is in the A readings. The relative (18) allows a collective reading, which is completely out for the comparative. On the other hand, the comparative (19) allows a distributive reading, which is impossible for the relative. I argue that in the case of comparative, every has wide scope over both DegP $\mathrm{P}_{\mathrm{MAX}}$ and $\operatorname{DegP}\left(\right.$ every $\left.>\operatorname{Deg} \mathrm{P}_{\mathrm{MAX}}>\operatorname{DegP}\right)$, but in the case of the relative, DegP $\mathrm{P}_{\mathrm{MAX}}$ scopes over every, and every scopes over DegP (DegP $\mathrm{PAX}_{\mathrm{M}}>$ every $>$ DegP).

${ }^{7}$ I use the equative, but the contrast holds for any comparative. 
a. Comparative: every $>\operatorname{Deg} \mathrm{P}_{\mathrm{MAX}}>\operatorname{DegP}$

- possible: distributive reading

- impossible: collective reading

b. Relative: $\operatorname{DegP} \mathrm{PAX}_{\mathrm{MAX}}>$ every $>$ DegP

- possible: marginally collective reading

- impossible: distributive reading

The scope reading for the comparative is the standard one, every guest has wide scope of the DegP $\mathrm{P}_{\text {MAX }}$ giving us the interpretation where we are talking about the person who spilled the most. Let me concentrate on what the scope relationship DegP $\mathrm{P}_{\mathrm{MAX}}>$ every $>$ DegP in (20b) entails for relative clause constructions like (18). DegP has the denotation of a set of degrees $\{D\}$. The operation Maximization takes the set of degrees $\{D\}$ and, on the basis of an established scale $\mathrm{S}$, returns the maximal degree $\mathrm{d}_{\max } \in\{\mathrm{D}\}$. In the case when DegP $\mathrm{P}_{\mathrm{MAX}}>$ every, this would mean that we are referring to an amount spilled by the guest who spilled the least, since the maximal degree has to apply to every guest, including the one that spilled the least. However, this reading is unattested, thus suggesting that $\mathrm{DegP}_{\mathrm{MAX}}>$ every is not possible. On its own this would suggest that DegP does not overtly raise out of CP but, at best, undergoes QR, as proposed in Grosu \& Landman (1998) for both amount relatives and comparatives. However, an approach where both (18) and (19) are derived identically via DegP QR fails to capture the differences in available readings. It would remain a mystery why the scope every $>\operatorname{Deg} \mathrm{P}_{\mathrm{MAX}}$ is attested for comparatives (distributive reading) but not for degree relatives (no distributive reading).

The second part of the scope equation in (20b) paints a different picture. For amount relative clauses the quantifier scopes over a non-Maximized Degree Phrase: every $>$ DegP. This scoping over a non-maximized set of degrees gives us the necessary scope for the collective reading. Let me argue that speakers adopt this reading since they have to exclude the first part of the equation in (20b) where: $\operatorname{Deg} \mathrm{P}_{\mathrm{MAX}}>$ every. This is because it violates the Kennedy-Heim generalization prohibiting a DegP from scoping over a quantifier (see Kennedy 1997, Heim 2001). ${ }^{8}$ In other words, the illegal scope relationship generated by the syntax is ignored. Such an

\footnotetext{
${ }^{8}$ It is beyond the scope of this paper to provide an account of the Kennedy-Heim constraint.
} 
approach captures the fact that in modal degree relative clauses overt DegP raising out of CP blocks a distributive reading, where: every $>\operatorname{DegP}_{\mathrm{MAX}}$. This is in contrast to comparatives, where the reading is allowed because DegP does not have to raise out of CP overtly or covertly. The lack of overt raising of DegP out of CP in comparatives allows every to have wide scope over DegP $\mathrm{P}_{\mathrm{MAX}}$, because the relationship between the quantifier and $\mathrm{DegP}$ in comparatives is established via QR. The proposal additionally predicts that the collective reading in relative clauses will be marginal, since it basically involves reconciling a syntactic requirement with semantic constraints. ${ }^{9}$

The difference between comparatives and relatives will then boil down to the fact that in relative clauses DegP is Maximized overtly and then raised out of CP thus blocking every $>$ $\operatorname{DegP}_{\text {Max }}$. This is because, in relative clauses, $\mathrm{QR}$ will not raise every above DegP $\mathrm{P}_{\text {Max }}$ since $\mathrm{QR}$ is $\mathrm{CP}$ bound. However, QR will raise every above the highest copy of a non-Maximized DegP in $\mathrm{CP}$, hence the possible collective reading in relative clauses. In comparatives, DegP $\mathrm{P}_{\text {Max }}$ does not raise out of $\mathrm{CP}$ and scope is established via $\mathrm{QR}$, allowing every to raise above the highest copy of DegP $P_{\text {MAX. }}$

(21) Scope in relative clause (dashed arrow line $=\mathrm{QR}$, solid arrow line = overt movement)

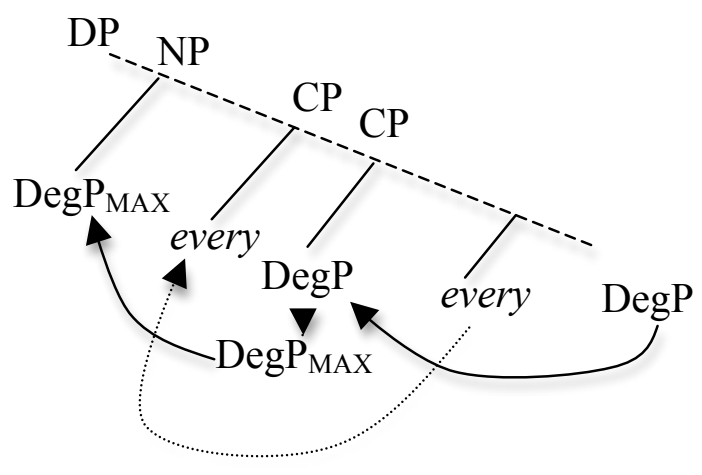

${ }^{9}$ It also opens the door for interesting speculation that scope and movement, overt or covert, are not necessarily in a 1-1 correspondence. 


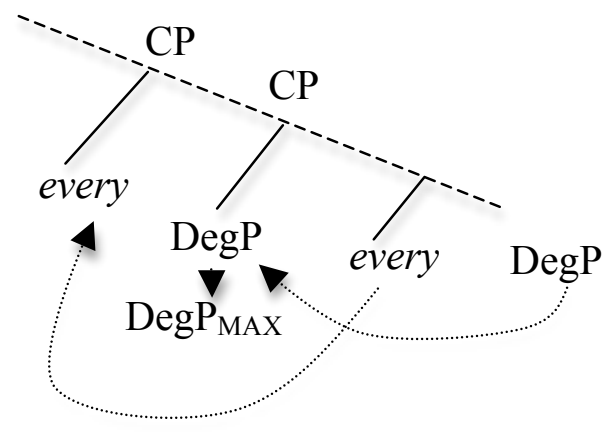

A word has to be said concerning the nature of DegP as adopted in Grosu and Landman (1998). They propose that a degree $d$ is a three membered set $d=<|x|, P, x>$, where $|x|$ is the value/cardinality, $\mathrm{P}$ is the measure domain, and $\mathrm{x}$ is the object measured. For examples like (1), the measure domain $\mathrm{P}$ is set to $\mathrm{P}=\mathrm{CHMPGN}$, the object measured $\mathrm{x}$, is set to $\mathrm{x}=\sqcup\{\mathrm{x} \in$ CHMPGN: SPILL ( $\mathrm{x})\}$, and the value $|\mathrm{x}|$ is set, for many of us, to $|\mathrm{x}|=$ number of bottles. ${ }^{10} \mathrm{I}$ am not arguing against such an approach, although later, following Rett (2008), I will adopt a simpler definition of a degree. What is being suggested here is that, in the case of relative clauses like (1), because DegP is forced to overtly raise out of CP, a translation of this proposal into system like Grosu and Landman (1998) would mean that the values of $\mathrm{x}$ and P are set derivationally in overt syntax. Using Grosu and Landman's nomenclature, the domain: $\mathrm{P}$ is established when DegP is merged with NP, and the object measured: $\mathrm{x}$ is computed when DegP merges with the CP. Note that the setting of $|x|$ as well as Maximization, are not syntactic operations, in the sense that they are not directly dependent on the structural configuration(s) that DegP enters into overtly or covertly (indirectly they are, because both operations take $\mathrm{P}$ and $\mathrm{x}$ as their input). We can assume that $|\mathrm{x}|$ is computed internally within DegP based on the values of $\mathrm{P}$ and $x$, and/or via scalar implicature. ${ }^{11}$ Maximization, on the other hand, appears to be an independent operation required for the semantics of comparison. Crucially, I suggest that the

\footnotetext{
${ }^{10} \mathrm{I}$ am simplifying here by assuming champagne is plural.

${ }^{11}$ It is well beyond the scope of this paper to discuss how $|\mathrm{x}|$ is computed (see Fox and Hackl 2006).
} 
setting of $\mathrm{x}$ and $\mathrm{P}$, which results in the establishment of $|\mathrm{x}|$, is carried out overtly for relative clauses. The mechanism is analogous to the establishment of theta-roles, or to wh-feature checking. This means that at the stage when $<|x|, P, x>$ is set for $d$ in DegP, then $d$ is set for every copy in the movement chain of DegP, including copies introduced into the derivation before these values were set. Maximization does not have such an effect. After $\mathrm{d}_{\max }$ is selected, only subsequent instances of DegP raisisng involve $d_{\max }$, lower copies of DegP are not affected. This distinction is crucial in order to compute the scope relations in (20). A Maximixed DegP in $\mathrm{CP}$ does not Maximize lower copies of DegP, but overt establishment of $<|x|, P, x>$ does impact every copy of DegP. This allows me to claim that, in relative clauses, when the quantifier every c-commands DegP in its base position, it has wide scope over a set of degrees whose triplets $<|\mathrm{x}|$, $\mathrm{P}, \mathrm{x}>$ are set.

\section{Two types of DegP}

Let me return to the examples in $(1,2)$ repeated here below.

$(23=1)$ It would take us all year to drink the champagne that you spilled at the party

(24=2) Juan no entendió lo hermosa que era la

Juan not understood the-neut. beautiful-fem.sg. that was the-fem.sg.

novella

novel- fem.sg.

'Juan did not understand how beautiful the novel was = Juan did not understand the extent of the beauty of the novel'

I have argued that (1) is derived via overt raising of DegP from a Spec-NP position inside the relative clause. Example (2) differs from (1) in that the gap in (2) appears to be an AP. Setting aside for now the matter whether there is a nominal head being modified by the CP in (2), let me concentrate on the issue concerning what is being raised out of the CP. Modern Spanish requires that the AP be outside the CP in examples like (2). This strongly suggests that it has been raised from the gap position inside the CP. I have argued that a degree relative clause 
requires DegP raising. This should apply to cases like (2) if they are also degree relative clauses. Examples like (2) have been argued to have a degree reading (Gutiérrez-Rexach 1999). What is being relativized is the degree of beauty (of the novel). Thus the truth conditions of (2) can be fulfilled if Juan knew that the novel is beautiful, he just did not know it was so beautiful. This means that (2) also requires overt DegP raising. Let me propose that we have DegP raising in (2) that, in contrast to (1), obligatorily forces the AP to raise. How is this possible? Let me propose that the difference between (1) and (2) lies in the nature of DegP. Neelman, van de Koot and Doetjes (2004) (NKD) argue that the grammar requires two kinds of Degree Phrases. One category, that they call class-1, takes the XP it modifies as its complement. The other category, called by them class-2, modifies a given XP by being in its Specifier.
Class-1
Class-2
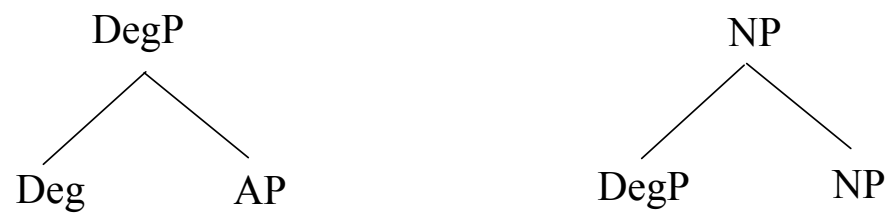

NKD argue that there are no semantic differences between class- 1 and class-2, and that the two classes are differentiated by their syntactic behavior. Not surprisingly, class-2 DegP's can move independently of the XP they modify, whereas class-1 DegP's cannot. Consider the following examples NKD gives for Dutch.

26. a. Ik acht hem [DegP te [AP afhankelijk van zijn vader]] om I consider him too dependent on his father for een eigen zaak te beginnen.

a own business to start

'I consider him too dependent on his father to start his own business' 
*b. $\quad \mathrm{Te}_{\mathrm{i}}$ acht $\mathrm{ik}$ hem [DegP $\mathrm{t}_{\mathrm{i}}$ [AP afhankelijk van zijn vader]] too consider I him dependent on his father om een eigen zaak te beginnen. for a own business to start

27. a. Ik acht hem [AP minder [AP afhankelijk van alcohol]] dan I consider him less dependent on alcohol than van andere drugs. on other drugs 'I consider him less dependent on alcohol than on other drugs'

?b. Minder ${ }_{i}$ acht $i k$ hem [AP $t_{i}$ [AP afhankelijk van alcohol]] dan van less consider I him dependent on alcohol than on andere drugs. other drugs

This taxonomy of DegP's allows me to argue that examples like (1) have a class-2 DegP, whereas examples like (2) involve a class-1 DegP. A class-1 DegP will necessarily move with its complement. In the case of (2) this would be the AP. ${ }^{12}$ On the other hand, a class-2 DegP has the option to raise without pied piping the phrase it modifies. In the case of (1) this would be the NP. What remains unaccounted is why pied piping is blocked altogether in modal degree relative clauses. If it was not, then, contrary to what was shown in (9) and (10), we should observe the

\footnotetext{
12 This was not always the case. As Gutiérrez-Rexach (1999) points out, historically in $16^{\text {th }}$ century Spanish the AP stayed inside the CP. This suggests that a class-2 DegP underwent a historical shift to a class-1 DegP.
}

(i) todos los que la loauan no dezian la meytad de lo que ella era all the-p1 that her praised not said the half of the-neut that she was hermosa beautiful 
availability of head noun reconstruction effects. In other words, there should be no Condition-A violations and idiom relativization ought to be possible. One possible solution is that the $\mathrm{DegP}$ in Spec-NP cannot pied pipe the NP. This, however, seems ad hoc. Let me suggest that the answer lies in the nature of Maximization operation. Maximization takes a set of degrees $\{D\}$ and returns the maximum degree contained in that set. In constructions like (2), the gradable adjective provides the scale for the degree phrase. Let me assume a standard semantics of gradable adjectives, scales and dimensions adopted from Rett (2008:3).

(28) "- Gradable adjectives are type $<\mathrm{e}$; $<\mathrm{d}$; $\mathrm{t}>>$, functions from individuals to sets of degrees (sets of degrees are also called 'scales')

- Scales are triples $\langle\mathrm{D},\langle\mathscr{A}, \psi\rangle$ with $\mathrm{D}$ a set of points, $>\mathscr{A}$ a total ordering on $\mathrm{D}$, and $\psi$ a dimension (e.g. 'height')

- Degrees $\mathrm{d}$ are therefore shorthand for triples $\langle\mathrm{d},\langle\mathscr{R}, \psi\rangle$ with $\mathrm{d}$ a point on a scale $\mathrm{D}$, $>\mathscr{A}$ a total ordering on $\mathrm{D}$, and $\psi$ a dimension. "

If we adopt such a definition of degrees, then Maximization of a DegP, with a gradable AP complement that serves as its dimension, is non problematic. Maximization selects the maximal degree from a set of degrees generated from a scale generated by merging DegP with the AP, in the case of (2), A= beauty. However, a DegP in the Spec of NP will be argued not to be able to undergo Maximization. It can be argued that an NP is simply the wrong input for Maximization. In other words, NP in Spec-CP will not trigger the operation. What is needed is a DegP in Spec-CP. This means that DegP in Spec-NP cannot pied pipe the NP to Spec-CP, or out of Spec-CP. Another issue is that the NP champagne is not gradable. In (1) what appears to be required to generate a scale is the $\mathrm{CP}$. This is because the $\mathrm{CP}$ functions like a gradable adjective. In this case the dimension is $\psi=<$ spilled $\mathrm{x}>$. When DegP is in Spec-CP the scale can be computed and a maximal degree can be selected. If DegP were to raise in Spec NP to Spec-CP, we can argue that Maximization will erroneously assume that the NP is the dimension for DegP. Since the noun champagne is not a gradable one (see Morzycki 2009), this will crash the input, 
because there is no scale to generate. ${ }^{13}$ Either assumption allows us to rule out NP pied piping in examples like (1). Such an approach implies that, in examples like (1), the CP plays the role of a gradable adjective. This appears to give us the correct meaning. The issue of whether a $\mathrm{CP}$ can be considered gradable is a separate matter. There is indication that CP's are more versatile in their semantic and syntactic roles that previously assumed (see Caponigro \& Polinsky 2011, for an example where relative clause CPs can play the role of indicative CPs). Another point indicating that this analysis might be on the right track is the observation that gradability is not solely restricted to gradable adjectives, or NP's, as research into gradable modals, VP and other categories has shown (see Lassiter 2011 for a review).

\section{Determiner restrictions}

Starting with the work in Carlson (1977), it has been observed that structures classified as degree, or degree of amount relative clauses, exhibit determiner restrictions. I will adopt the account proposed in Grosu \& Landman (1998:146), namely that "the only determiners that preserve max into the quantification are the universals like every and definites like the. Hence, these are the only determiners that can head a DP with a degree relative." It has to be noted that although I reject Grosu \& Landman's derivation of degree relatives, the restriction on

${ }^{13}$ One indication that gradability of the NP plays a role comes from the fact that a degree of amount reading in idiom relativization is more acceptable with gradable nouns than with nongradable nouns. Compare (i) with (ii).

(i) It would take us all year to report on the headway you made in a week

\#(ii) At the morgue, it would take us just a day to get the creeps that a cemetery gives in a year The noun headway has an inherent amount reading, for example if we modify it with the adjective like big, enormous we obtain an amount modification (enormous headway = a large amount of headway). This is not so obvious with a noun like creeps, and is clearly not the case with noun like champagne. This suggests that gradable NP's can be pipe piped. I would like to thank Edwin Williams p.c. for pointing out to me the issue of gradablity in Nouns. 
determiners is compatible with my proposal, since DegP has already Maximized in CP when it raises into the extended projection of the external head noun.

The example in (2) has another interesting property, namely that there is lack of gender agreement between the Determiner and Adjective. I will argue that this is a reflex on the restriction on multiple agreement, and a further argument that the DegP with AP raises from within the CP. Gutiérrez-Rexach (1999) proposes that the construction in (2) is headed by a null pronominal, and that this configuration triggers neuter agreement with the determiner. The AP cannot agree with the null NP or the determiner since it has been raised as part of DegP, and it has undergone agreement with the internal DP

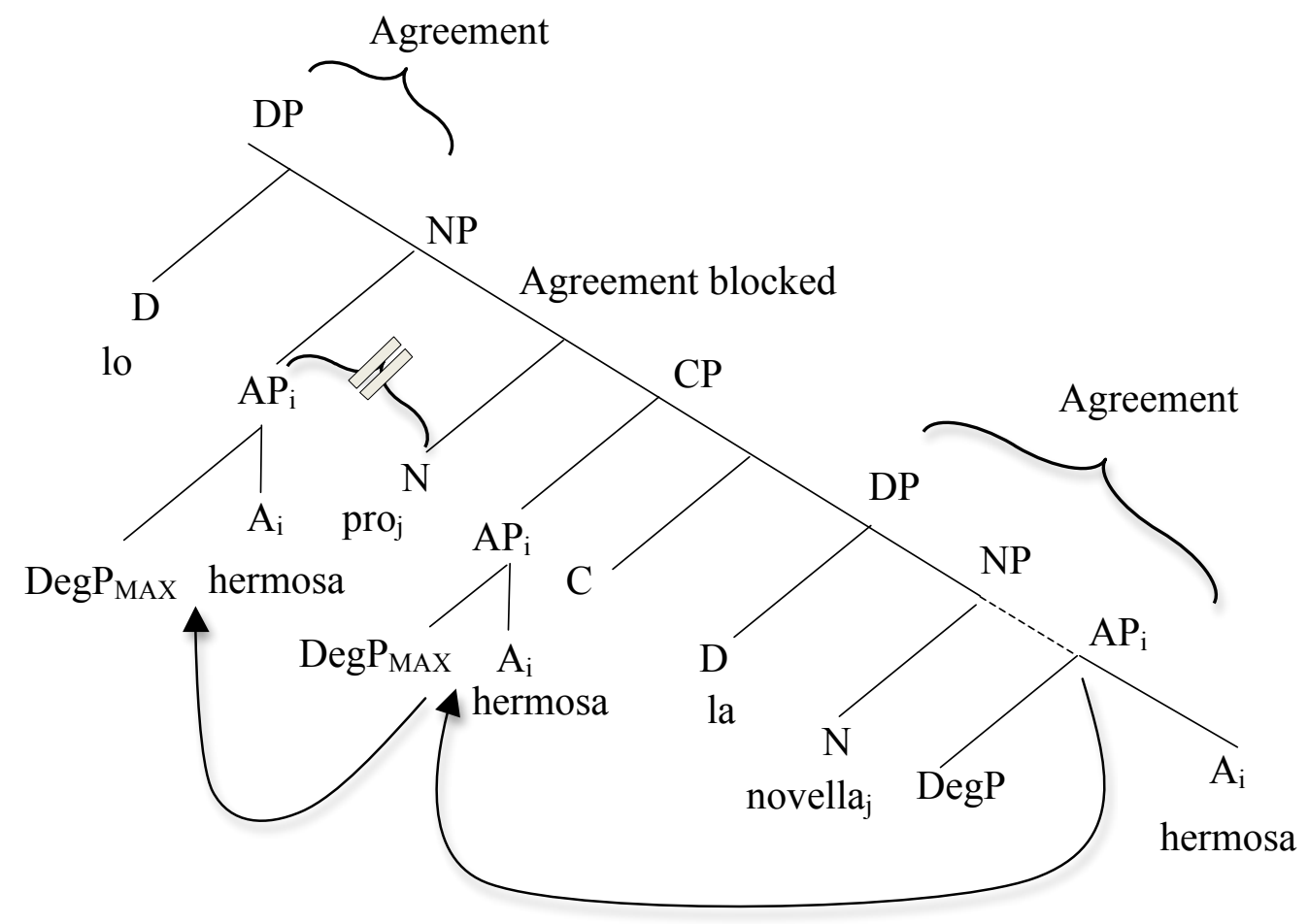

The analysis relies on the fact that the AP raises with its agreement features inert. I do not assume any specific agreement mechanism for inside the $\mathrm{CP}$, it is not that important for our analysis. Predicative AP's agree with their subjects in Spanish, and the mechanism should be the same, regardless if the CP is part of a relative clause or not. Crucially, once an AP participates in an agreement configuration, it cannot do so again. 


\section{Conclusion}

In this paper I have argued that a certain type of degree relative clause is best analyzed as involving overt DegP raising. Evidence for such an approach comes from head noun reconstruction facts, as well as asymmetries between degree relatives and comparatives as far as the interaction with scope bearing quantifiers like every. This work did not examine classical amount/degree relative clauses discussed in Carlson (1977). This is because of two reasons. First of all, there are proposals in the literature, McNally (2008) that 'there' relative clauses do not involve degree relativization. The same has been argued for ACD relatives (Herdan 2008), which would indicate that a semantic criterion of relativizing amounts does not yield a homogenous class of constructions. Furthermore, a discussion of possible forms of degree relativization is beyond the scope of this paper for reasons of space. The primary goal of this paper is to show that relative clauses can be formed via overt DegP raising which gives rise to specific semantics and syntax. Having said that, I will try to tentatively speculate on how to go about and account for 'there' relatives, because I believe that the approach outlined here has the potential to capture the behavior of 'there' type relative clauses. Heim (1987) argues that the complementizer restriction on relative clauses stems from the fact that the gap position $e$ in 'there' relative clauses (30a) is subject to the definiteness effect (Milsark 1974), just as is the gap in (30b).

a. John took the books that $/ *$ which there were $e$ on the table

b. It would take us a year to drink the champagne that $/{ }^{*}$ which you spilled $e$ at the party

Setting aside the details of the individual proposals (see Heim 1987, Carlson 1977, Milsark 1974, and Grosu \& Landman 1998 for an overview), the general observation, following Heim (1987), is: a that complementizer is possible in both constructions in (30) since it is compatible with the gap being associated with degree variable, which counts as a weak DP. On the other hand, the relative pronoun which is not compatible with a DegP gap because it requires 
a strong DP. ${ }^{14}$ The crucial generalization for our discussion is that the relative marker restriction in a 'there' relative clause of the type in (30a) points to a DegP trace. I have provided evidence why (30b) should be assumed to have a DegP raising account. In the same vein, I would like to suggest that a 'there' relative clause like (30a) should also involve DegP raising. This would account for the similar complementizer restrictions. However, I suggest that (30a), unlike (30b), involves a class-1 DegP phrase. This means that the whole extended NP projection, including AP and NumP slots (Cinque 2010, Zamparelli 2000), is raised with the DegP in (30a). Obviously, this raises a whole set of questions concerning the syntax and semantics of such constructions. I will just mention two. First of all, an approach where the NP is forced to raise should show in reconstruction effects. As observed by Sauerland (2003), 'there' relatives (31a) do not alleviate Condition-C effects, in contrast to modal degree of amount relatives (31b).

(31) *a. It would have taken us all year to read the letters for $\mathrm{John}_{\mathrm{i}}$ that he $\mathrm{e}_{\mathrm{i}}$ expected there would be

b. It would have taken us all year to read the letters for $J_{o h n}$ that he $e_{i}$ had burned after his girlfriend left

As far as the contrast between (31a), a 'there' relative and (31b), a modal degree relative, is valid, the analysis appears to be on the right track. A class-2 DegP cannot pied pipe an NP so there should be no Condition C violation, whereas a class-1 DegP raises with NP as its

${ }^{14}$ Additional evidence that a complementizer relative marker is compatible with a DegP trace, whereas a relative pronoun one is not, comes from languages like Polish, or Russian, where equatives are possible with a complementizer but not with a relative pronoun (in the case of Polish this complementizer is restricted to relative clauses):

(i) $\quad \mathrm{W}$ domu jest tyle piwa co/*które wina jest w pracy

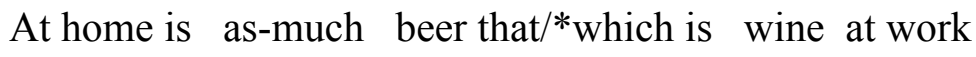

'At home there is as much beer as there is wine at work'

This is on top of the existing regular equative marker that these languages employ. 
complement. This is captured in the reconstruction facts. ${ }^{15}$ It has to be stressed that I am not suggesting there is a head noun raising derivation of 'there' relative clauses. The NP raises out of $\mathrm{CP}$ "by accident" because there is no other way for DegP to raise out of CP.

The second point involves the interpretation of 'there' relative clauses. As pointed out in McNally (2008) and Herdan (2008), they do not have an identity of amount reading, but rather an identity of substance, one that involves exhaustive reading of amount. Herdan (2008) proposes that 'there' relative clauses are generated via a covert superlative morpheme. Without discussing the details of her analysis, I suggest that a class-1 DegP raised together with its NP complement to Spec-CP, where it becomes Maximized, achieves the same semantic effect that a null superlative morpheme would. In both cases, we select the maximal degree out of a set of degrees on a given scale on a defined dimension. In other words, if we take an expression: the tallest person the superlative can characterize the maximal degree on a scale whose dimension is tallness (and the object is the person). The issue remains where do we obtain the scale in 'there' relatives. We could argue that a null AP is present in (30a), or, as I will suggest, that there is a NumP containing the plural that provides us with a dimension - a number one. That is why plurality is essential in (30a), otherwise wee need a superlative to maximize the DegP.

(32) *a. It would take us a year to read the letter that he knew there would be in the safe

b. It would take us a year to read the letters that he knew there would be in the safe

c. It would take us a year to read the only letter that he knew there would be in the safe

${ }^{15}$ I skip the issue how important the lack of Condition-C effects is in distinguishing a head noun raising derivation from a matching one (see Sauerland $(1998,2003)$ for a discussion on the availability of Vehicle Change (Fiengo and May 1994) to apply to elided under identity NP's). An anonymous reviewer has pointed out to me that assuming that reconstruction facts can be handled in both approaches, then my argument hinges on the idiom relativization facts. I disagree, I think that when one takes the evidence provided in this paper in its totality, there is a strong argument that $\mathrm{DegP}$ raises out of $\mathrm{CP}$ in degree relative clauses. 
Such an approach to 'there' relative clauses would make them similar to the Spanish construction in (2). Both involve class-1 DegP raising. The difference being that in Spanish the DegP has an AP complement, whereas 'there' relatives have a plural NP. However, in both cases we get a Maximality interpretation. In the Spanish example we have an exclamative AP - the novel was so beautiful, whereas in 'there' relatives we have an exhaustive interpretation of amount. $^{16}$

Finally, there is an unfortunate shortcoming of this paper in that there is no discussion of why modal degree relative clauses like (1) require a modal. McNally (2008) notes some exceptions, but in most cases removing the modal gives rise to an identity of substance reading. Again, for reasons of space, I can only offer speculation as to why this is the case. Modal amount relative clauses involve comparison, and yet are derived via just one instance of DegP. A possible account of this requirement comes from the analysis of modals in $\operatorname{Kratzer}(1981,1986)$, where she argues that modals allow for quantification over possible worlds. One can speculate on the consequences of the interaction between modal scope and the scope of the raised DegP. The aim would be to explore whether when DegP has to scope over the modal in order to allow us to establish a comparison between degrees in two distinct possible worlds expressed by the prepositions in (1), namely: $\mathrm{d}_{w 1}=$ amount spilled and $\mathrm{d}_{w 2}=$ amount drank, and have a mapping where (1) is true iff $\mathrm{d}_{w 1}=\mathrm{d}_{w 2}$. In such a scenario, the DegP would need a modal in order to scope over it (but see Lassiter 2011 for an account where modals take a DegP as their modifier, and a semantics that does not require a possible worlds account). I leave this issue for future research.

\footnotetext{
${ }^{16}$ One can ask, why relative clause like (1) cannot have DegP raise to Spec-Num which would provide the scale. My suspicion is that a class-2 DegP cannot raise to Spec-NumP and compute a scale.
} 


\section{References}

Bianchi, Valentina. 1999. Consequences of Antisymmetry: Headed Relative Clauses. Berlin: Mouton de Gruyter.

Carlson, Greg. 1977. Amount relatives. Language 53(3): 520-542.

Caponigro, Ivano \& Polinsky, Maria. 2011. Relative embeddings: A Circassian puzzle for the syntax/semantics interface. Natural Language and Linguistic Theory 29(1): 71-122.

Chomsky, Noam. 1965. Aspects of the Theory of Syntax. Cambridge, MA: MIT Press.

Cinque, Guglielmo. 2010. The Syntax of Adjectives. A Comparative Study. Cambridge, MA: MIT Press.

Fiengo, Robert \& May, Robert. 1994. Indices and Identity. Cambridge, MA: MIT Press.

Fox, Danny \& Hackl, Martin. 2006. The universal density of measurement. Linguistics and Philosophy 29(5): 537-586.

Grosu, Alexander \& Landman, Fred. 1998. Strange relatives of the third kind. Natural Language Semantics 6(2): 125-170.

Gutiérrez-Rexach, Javier. 1999. The structure and interpretation of Spanish degree neuter constructions. Lingua 109(1): 35-63.

Heim, Irene. 1987. Where does the definiteness restriction apply? Evidence from the definiteness of variables. In The Representation of (In)definiteness, Eric Reuland \& Alice ter Meulen (eds), 21-42. Cambridge, MA: MIT Press.

Heim, Irene. 2001. Degree operators and scope. In Audiatur Vox Sapientiae. A Festschrift for Arnim von Stechow, Caroline Féry \& Wolfgang Sternefeld, (eds), 214 239. Berlin: Akademie Verlag.

Herdan, Simona. 2008. Degree Amounts in Relative Clauses. PhD dissertation, University of Connecticut.

Huang, C.-T. James. 1984. On the distribution and reference of empty pronouns. Linguistic Inquiry 15(2): 531-574.

Kayne, Richard. 1994. The Antisymmetry of Syntax. Cambridge, MA: MIT Press.

Kennedy, Christopher. 1997. Projecting the Adjective: The Syntax and Semantics of Gradability and Comparison. PhD dissertation, UC Santa Cruz. 
Kratzer, Angelika. 1981. The notional category of modality. In Words, Worlds, and Contexts: New Approaches in Word Semantics, Hans-Jurgen Eikmeyer \& Hannes Rieser (eds): 3874. Berlin: Mouton de Gruyter.

Kratzer, Angelika. 1986. Conditionals. Chicago Linguistics Society 22(2): 1-15.

Lassiter, Daniel. 2011. Measurement and Modality. The Scalar Basis of Modal Semantics. PhD dissertation, New York University.

Lees, Robert. 1960. A multiply ambiguous adjectival construction in English. Language 36(2): 207-221.

McNally, Luise. 2008. DP-internal only, amount relatives, and relatives out of existentials. Linguistic Inquiry 39(1): 161-169.

Merchant, Jason. 2001. The Syntax of Silence. Oxford: Oxford University Press.

Milsark, Gary. 1974. Existential sentences in English. PhD dissertation, MIT.

Morzycki, Marcin. 2009. Degree modification of gradable nouns: size adjectives and adnominal degree morphemes. Natural Language Semantics 17(2): 175-203.

Munn, Alan. 1994. A Minimalist Account of Reconstruction Asymmetries. In Proceedings of NELS 24, Mario Gonzàlez (ed), 397-410. Amherst, MA: GLSA, University of Massachusetts.

Neelman Ad, van de Koot, Hans \& Doetjes, Jenny. 2004. Degree Expressions The Linguistic Review 21(1): 1-66.

Rett, Jessica. 2008. Degree Modification in Natural Language. PhD dissertation, University of New Jersey, Rutgers.

Rizzi, Luigi. 1997. The fine structure of the left periphery. In Elements of Grammar: Handbook of Generative Syntax, Liliane Haegeman (ed), 281-337. Dordrecht: Kluwer.

Ross, John, R. 1982. Pronoun deleting processes in German. Paper presented at the Annual Meeting of the Linguistic Society of America, San Diego, California.

Sauerland, Uli. 1998. The Meaning of Chains. PhD dissertation, MIT.

Sauerland, Uli. 2003. Unpronounced heads in relative clauses. In The Interfaces: Deriving and Interpreting Omitted Structures, Karl Schwabe \& Suzanne Winkler (eds), 205-226. Amsterdam: John Benjamins.

von Stechow, Arnim. 1984. Comparing theories of comparison. Journal of Semantics (3): 1-77. 
Svenonius, Peter. 2005. Extending the extension condition to discontinuous idioms. Linguistic Variation Yearbook 5(1): 227-263.

Szczegielniak, Adam. 2005. Relativization that you did.... MIT Occasional Papers in Linguistics (24).

Vergnaud, Roger. 1974. French Relative Clauses. PhD dissertation, MIT.

de Vries, Mark. 2002. The Syntax of Relativization. PhD dissertation, University of Amsterdam.

Zamparelli, Roberto. 2000. Layers in the Determiner Phrase. PhD dissertation, University of Rochester. 